\title{
A Rare Combination of Chromosomal Abnormalities in an Infant With Turner Syndrome and Hypoplastic Left Heart Syndrome
}

\author{
Roya Huseynova ${ }^{1}$, Latifa Bin Mahmoud ${ }^{1}$, Abduljabbbar Alshenqiti ${ }^{2}$, Khalid Alomran ${ }^{3}$, Nabeel Alodaidan \\ 1 , Ogtay Huseynov ${ }^{4}$ \\ 1. Neonatal Intensive Care Unit, King Saud Medical City, Riyadh, SAU 2. Genetic and Metabolic Unit, King Saud Medical \\ City, Riyadh, SAU 3. Cardiology, King Saud Medical City, Riyadh, SAU 4. Neurosurgery, Azerbaijan Medical University, \\ Baku, AZE
}

Corresponding author: Roya Huseynova, huseynova_roya@yahoo.com

\section{Abstract \\ Hypoplastic left heart syndrome (HLHS) is a fatal congenital complex heart defect where the heart's left side is critically undeveloped. However, its pathogenesis remains unknown. We report a unique case of HLHS because of the rare combination of two abnormalities in the cell lines: partial monosomy X (Turner syndrome) and partial trisomy 14 (14q11.2 microduplication syndrome).}

Review began 06/24/2021 Review ended 07/05/2021 Published 07/20/2021

๑) Copyright 2021 Huseynova et al. This is an open access article distributed under the terms of the Creative Commons Attribution License CC-BY 4.0., which permits unrestricted use, distribution, and reproduction in any medium, provided the original author and source are credited.
Categories: Cardiology, Genetics, Pediatrics

Keywords: hypoplastic left heart syndrome, translocation, neonates, turner syndrome, 14q11.2 microduplication syndrome

\section{Introduction}

Hypoplastic left heart syndrome (HLHS) is a congenital heart defect constituting $2 \%$ to $9 \%$ of all congenital heart diseases [1]. The mortality rate accounts for $25 \%$ of neonatal cardiac deaths [2,3]. This cardiac structural defect includes varying degrees of the left ventricle's underdevelopment, hypoplasia of the aorta, aortic valve and mitral valve stenosis, or atresia [2]. The management options of HLHS include comfort care, surgical-staged Norwood surgery, and cardiac transplantation.

The etiology of HLHS is multifactorial and includes maternal, infectious, immunosuppressive, and genetic factors [4]. Although there is growing data which are supporting a genetic etiology, no specific gene has been identified until now [5-7]. Some reports have concluded that HLHS is heterogeneous in etiology [8]. The outcome in HLHS is significant influenced by the presence of chromosomal and other noncardiac abnormalities.

We present a unique case of HLHS because of the rare combination of two abnormalities in the cell lines: partial monosomy X (Turner syndrome) and partial trisomy 14 (14q11.2 microduplication syndrome).

\section{Case Presentation}

A term girl, small for gestational age, the first baby of the first degree consanguineous couple, was born to a 29 -year-old mother by spontaneous vaginal delivery. The pregnancy was insignificant, and there was no history of radiation exposure or drug intake in any trimester; no family history of congenital heart disease or any chromosomal disorders.

A prenatal ultrasound scan at 30 weeks of gestation revealed a hypoplastic left ventricle defect, with no extracardiac malformations. Fetal echocardiography reported hypoplastic left heart, atrial septal defect, and patent ductus arteriosus. Amniocentesis was done at 32 weeks of gestational age, and chromosomal microarray analysis (CMA) revealed partial monosomy and partial trisomy.

An approximately 63 megabases large pathogenic one copy loss (heterozygous deletion) encompassing the entire small arm of the chromosome X (Xp) and extending to the long arm of chromosome X (Xq), X p22.33q11.2 arr[GRCh37] Xp22.33q11.2(168546_63625851)x1) containing 447genes was detected. Furthermore, an approximately 50 megabases large pathogenic one copy gain (duplication) of the chromosomal region 14q11.2q24.2 arr[GRCh37] 14q11.2q24.2(20511672_70922704)x3) containing 437 genes was determined. These findings are suggestive of a chromosome translocation involving the chromosomes $\mathrm{X}$ and 14.

The infant cried immediately after birth and required only the initial steps of resuscitation. The Apgar scores were eight and nine at one and 10 minutes, respectively. Birthweight was 2270 grams (below fifth percentile), the length was $48 \mathrm{~cm}$ (25th centile), and head circumference was $32 \mathrm{~cm}$ (below fifth percentile). 


\section{Cureus}

Clinical examination showed a neonate with no apparent dysmorphic features with mild tachypnea (respiratory rate: 65 breaths per minute) and tachycardia (heart rate: 170 beats per minute). The patient's arterial blood gases report was $\mathrm{pH}-7.30, \mathrm{PaCO} 247 \mathrm{mmHg}$, base deficit -2 (BE-2); blood pressure was 62/40 $\mathrm{mmHg}$, and oxygen saturation was $90 \%$ at room air. She had vesicular breath sounds with few fine basal crepitations. The first and second heart sounds were normal intensity, but with a systolic murmur grade three of six with maximal intensity at the left lower sternal edge.

The postnatal echocardiography report confirmed the diagnosis of HLHS with the hypoplastic left ventricle, mitral atresia, aortic atresia, and moderate tricuspid regurgitation (Figures 1,2).

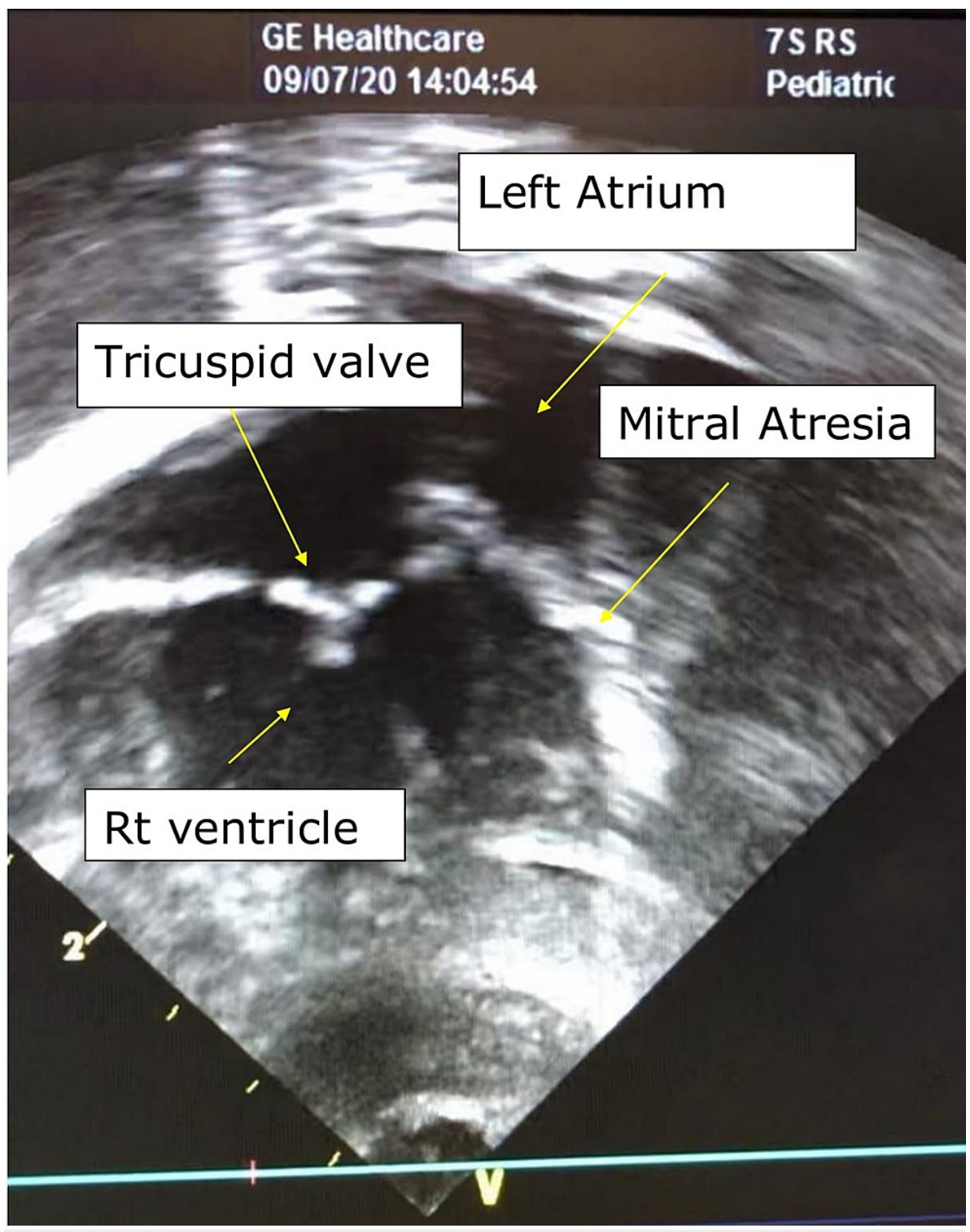

FIGURE 1: Echocardiography findings - apical four-chamber view shows atretic mitral valve and severe hypoplastic left ventricle 


\section{Cureus}

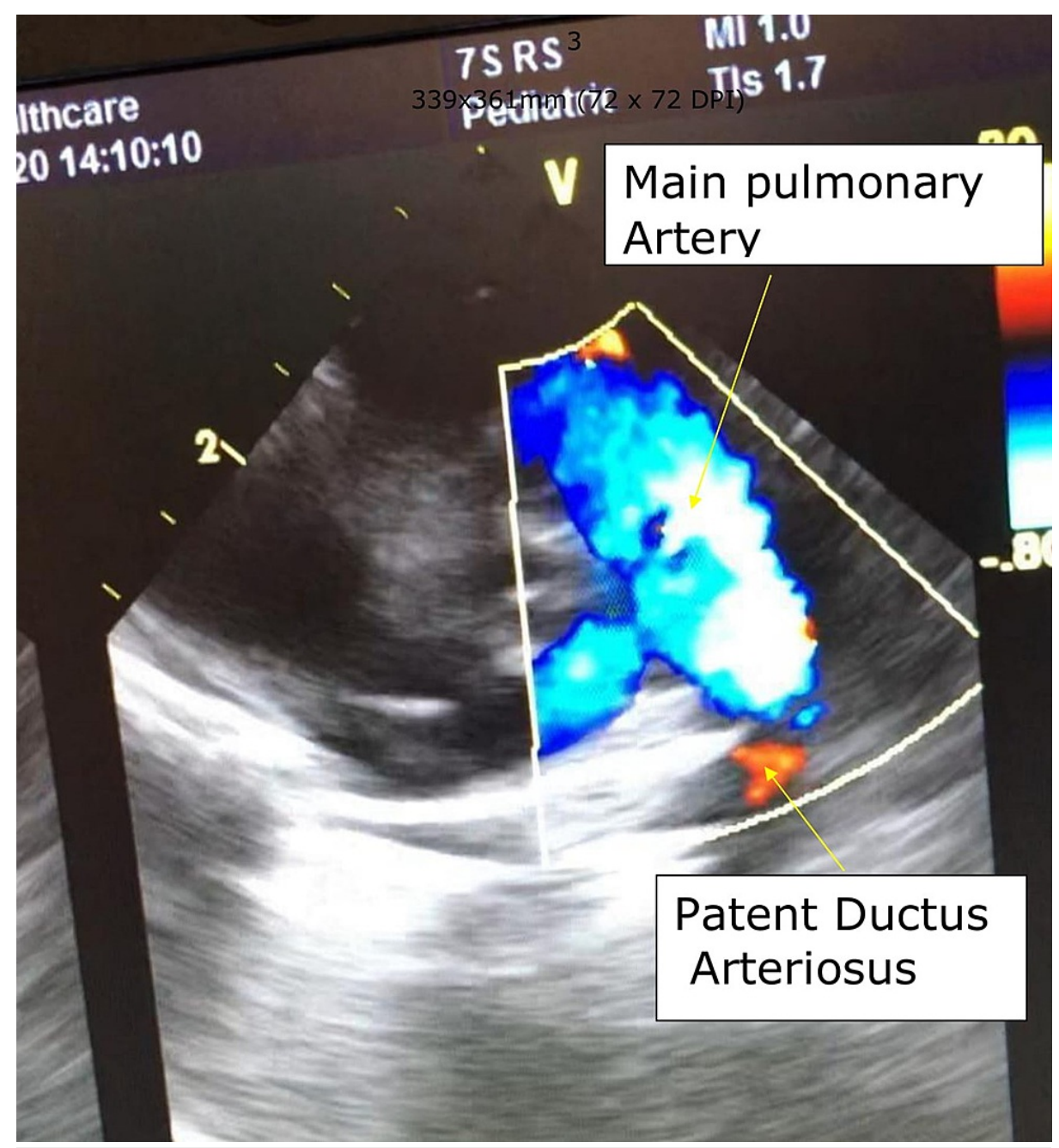

FIGURE 2: Short axis view shows main pulmonary artery and ductus arteriosus supplying the distal part of arch of the aorta

The neonate was started on prostaglandin infusion treatment. Physical examination of other systems on admission was normal with stable hemodynamic values. Laboratory blood tests showed normal ranges of white blood cells, hemoglobin, and platelet counts. Abdomen ultrasonography and magnetic resonance imaging of the brain were unremarkable. A patient was diagnosed to have HLHS with partial monosomy X (Turner syndrome) and partial trisomy 14 (14q11.2 microduplication syndrome). We explained to parents the expected poor outcome of the management option of such cardiac defects; as a result, parents accepted the option of comfort care. The patient passed away on the seventh day of life.

\section{Discussion}

The association of the HLHS with Turner syndrome (TS) was reported to be $13.2 \%$; though, only $2.5 \%$ of HLHS cases presented with TS $[9,10]$. The survival rate for infants with HLHS following the Norwood procedure at five years and 10 years can reach more than $65 \%$ and $55 \%$, respectively [11]. However, the TS diagnosis in the patients with HLHS increased the mortality rate up to $80 \%[8,10,12]$. Several other genetic disorders like Holt-Oram, Noonan syndrome, trisomy 21, trisomy 13, and trisomy 18 may also coexist with HLHS $[13,14]$.

Chromosomal microdeletions and duplications appear to be another risk factor for the HLHS and can occur in up to $10 \%$ [15]. Microduplication syndrome 14q11.2 is a rare chromosomal aberrations condition characterized by hypotonia, mental retardation, developmental delay, and subtle dysmorphic craniofacial features [16].

Complete trisomy 14 has a high rate of fetal mortality, while live born chance increased with the mosaic type of trisomy 14 [17]. Çetin et al. described a case of 14q11.2 microduplication with West syndrome (infantile spasms, hypsarrhythmia, and intellectual disability) [18]. Other manifestations of 14q11.2 microduplication include microcephaly, behavior disturbance, obesity, and speech delay [19]. 
Turner phenotype is very variable, even in cases with a similar karyotype, though there are some common presentations like gonadal dysgenesis, skeletal malformations, and short stature. Furthermore, dysmorphic craniofacial features are not essential in neither 14q11.2 microduplication syndrome nor Turner syndrome [20,21]. Some cases, because of minimal clinical features and normal stature, will be diagnosed in adolescence as a part of a fertility assessment due to premature ovarian failure [22].

Leppig and Disteche reported that only cases with rings or fragments derived from the X chromosome would have a more severe phenotype that also depends on size, origin, the status of the $\mathrm{X}$ inactivation, and genes affected by copy number variations [23]. The absence of dysmorphic features in the presented case highlights the need for a genetic investigation in all patients with HLHS, even in non-dysmorphic neonates. Some authors mentioned the importance of CHD8 and SUPT16H genes in the pathogenesis of 14q11.2 microduplication syndrome [16,19]. Both CHD8 and SUPT16H genes are within the chromosomal region $14 \mathrm{q} 11.2 \mathrm{q} 24.2$ found in our case.

Pathogenic variants in the MYH6 gene are a well-known cause of hypertrophic cardiomyopathy and dilated cardiomyopathy (MIM \# 613251 and MIM \# 613252). Pathogenic variants in the MYH6 gene also can cause structural heart abnormality, especially atrial septal defect [24,25]. Moreover, Theis et al. described heterozygosity for recessive MYH6 mutations in cases with HLHS that implicate a common molecular source for the latent myopathy of both ventricles [26]. Min-Su-Kim et al suggest that fetal heart development depends on proper blood flow. Furthermore, hemodynamic changes ensued due to the sarcomere disorganization may affect the development of the left ventricle [27]. Association of myosin-6 variants in patients with HLHS decreased cardiac transplant-free survival rate comparing with HLHS without myosin-6 variants [27,28]. The MYH6 gene is duplicated in our patient because it is located within the chromosomal region $14 \mathrm{q} 11.2 \mathrm{q} 24.2$.

Clinical manifestations and degree of mental retardation of $14 \mathrm{q} 11.2$ microduplication syndrome depend on the duplication size, which varies from small (e.g., 35 kilobases) to large size (e.g.,50 megabases). The presence of duplication and deletion in the case indicates these abnormalities may happen from a balanced translocation in one of the parents, encouraging us to send chromosomal analysis for parents to prove it.

Although HLHS association with Turner syndrome is well known, 14q11.2 microduplication with Turner syndrome and HLHS was not reported. Assumed the possibility of genetic heterogeneity of HLHS, antenatal genetic work-up should be standard in these cases.

\section{Conclusions}

HLHS is one of the common cardiac defects that can be detected on prenatal sonography. Timely provided prenatal ultrasonography and prompt genetic investigation for each case of HLHS may reveal the natural origin of this complex congenital heart disease that is essential for determining the optimal decisioninterventions options for physicians and parents.

\section{Additional Information \\ Disclosures}

Human subjects: Consent was obtained or waived by all participants in this study. Conflicts of interest: In compliance with the ICMJE uniform disclosure form, all authors declare the following: Payment/services info: All authors have declared that no financial support was received from any organization for the submitted work. Financial relationships: All authors have declared that they have no financial relationships at present or within the previous three years with any organizations that might have an interest in the submitted work. Other relationships: All authors have declared that there are no other relationships or activities that could appear to have influenced the submitted work.

\section{References}

1. Fruitman DS: Hypoplastic left heart syndrome: prognosis and management options . Paediatr Child Health. 2000, 5:219-25. 10.1093/pch/5.4.219

2. Caplan WD, Cooper TR, Garcia-Prats JA, Brody BA: Diffusion of innovative approaches to managing hypoplastic left heart syndrome. Arch Pediatr Adolesc Med. 1996, 150:487-90. 10.1001/archpedi.1996.02170300041008

3. Perloff JK: The hypoplastic left heart. The Clinical Recognition of Congenital Heart Disease. WB Saunders Co., Philadelphia, USA; 1994. 4th ed.:727-37.

4. Connor JA, Thiagarajan R: Hypoplastic left heart syndrome. Orphanet J Rare Dis. 2007, 2:23. 10.1186/17501172-2-23

5. Shokeir MH: Hypoplastic left heart syndrome: an autosomal recessive disorder . Clin Genet. 1971, 2:7-14. 10.1111/j.1399-0004.1971.tb00249.x

6. Wessels MW, Berger RM, Frohn-Mulder IM, et al.: Autosomal dominant inheritance of left ventricular outflow tract obstruction. Am J Med Genet A. 2005, 134A:171-9. 10.1002/ajmg.a.30601

7. Cohen DM, Allen HD: New developments in the treatment of hypoplastic left heart syndrome . Curr Opin Cardiol. 1997, 12:44-50. 10.1097/00001573-199701000-00008 
8. Yagi H, Liu X, Gabriel GC, et al.: The genetic landscape of hypoplastic left heart syndrome . Pediatr Cardiol. 2018, 39:1069-81. 10.1007/s00246-018-1861-4

9. Surerus E, Huggon IC, Allan LD: Turner's syndrome in fetal life. Ultrasound Obstet Gynecol. 2003, 22:264-7. 10.1002/uog.151

10. Reis PM, Punch MR, Bove EL, van de Ven CJ: Outcome of infants with hypoplastic left heart and Turner syndromes. Obstet Gynecol. 1999, 93:532-5. 10.1016/s0029-7844(98)00462-1

11. Barron DJ, Kilby MD, Davies B, Wright JG, Jones TJ, Brawn WJ: Hypoplastic left heart syndrome. Lancet. 2009, 374:551-64. 10.1016/S0140-6736(09)60563-8

12. van Egmond H, Orye E, Praet M, Coppens M, Devloo-Blancquaert A: Hypoplastic left heart syndrome and 45X karyotype. Br Heart J. 1988, 60:69-71. 10.1136/hrt.60.1.69

13. Gillum RF: Epidemiology of congenital heart disease in the United States . Progress Cardiol. 1994, 127:91927. 10.1016/0002-8703(94)90562-2

14. Glauser TA, Rorke LB, Weinberg PM, Clancy RR: Congenital brain anomalies associated with the hypoplastic left heart syndrome. Pediatrics. 1990, 85:984-90.

15. Carey AS, Liang L, Edwards J, et al.: Effect of copy number variants on outcomes for infants with single ventricle heart defects. Circ Cardiovasc Genet. 2013, 6:444-51. 10.1161/CIRCGENETICS.113.000189

16. Smyk M, Poluha A, Jaszczuk I, Bartnik M, Bernaciak J, Nowakowska B: Novel 14q11.2 microduplication including the CHD8 and SUPT16H genes associated with developmental delay. Am J Med Genet A. 2016, 170:1325-9. 10.1002/ajmg.a.37579

17. Shinawi M, Shao L, Jeng LJ, et al.: Low-level mosaicism of trisomy 14: phenotypic and molecular characterization. Am J Med Genet A. 2008, 146A:1395-405. 10.1002/ajmg.a.32287

18. Çetin ÖE, Yalçınkaya C, Karaman B, Demirbilek V, Tüysüz B: Chromosome 14q11.2-q21.1 duplication: a rare cause of West syndrome. Epileptic Disord. 2018, 20:219-24. 10.1684/epd.2018.0972

19. Pascolini G, Agolini E, Fleischer N, et al.: Further delineation of the neurodevelopmental phenotypic spectrum associated to 14q11.2 microduplication. Neurol Sci. 2020, 41:3751-3. 10.1007/s10072-020-04510-6

20. Smol T, Thuillier C, Boudry-Labis E, et al.: Neurodevelopmental phenotype associated with CHD8-SUPT16H duplication. Neurogenetics. 2020, 21:67-72. 10.1007/s10048-019-00599-W

21. Loscalzo ML: Turner syndrome. Pediatr Rev. 2008, 29:219-27. 10.1542/pir.29-7-219

22. Beke A, Piko H, Haltrich I, et al.: Molecular cytogenetic analysis of Xq critical regions in premature ovarian failure. Mol Cytogenet. 2013, 6:62. 10.1186/1755-8166-6-62

23. Leppig KA, Disteche CM: Ring X and other structural X chromosome abnormalities: $\mathrm{X}$ inactivation and phenotype. Semin Reprod Med. 2001, 19:147-57. 10.1055/s-2001-15395

24. Ching YH, Ghosh TK, Cross SJ, et al.: Mutation in myosin heavy chain 6 causes atrial septal defect . Nat Genet. 2005, 37:423-8. 10.1038/ng1526

25. Granados-Riveron JT, Ghosh TK, Pope M, et al.: Alpha-cardiac myosin heavy chain (MYH6) mutations affecting myofibril formation are associated with congenital heart defects. Hum Mol Genet. 2010, 19:400716. $10.1093 / \mathrm{hmg} / \mathrm{ddq} 315$

26. Theis JL, Zimmermann MT, Evans JM, et al.: Recessive MYH6 mutations in hypoplastic left heart with reduced ejection fraction. Circ Cardiovasc Genet. 2015, 8:564-71. 10.1161/CIRCGENETICS.115.001070

27. Kim MS, Fleres B, Lovett J, et al.: Contractility of induced pluripotent stem cell-cardiomyocytes with an MYH6 head domain variant associated with hypoplastic left heart syndrome. Front Cell Dev Biol. 2020, 8:440. 10.3389/fcell.2020.00440

28. Tomita-Mitchell A, Stamm KD, Mahnke DK, et al.: Impact of MYH6 variants in hypoplastic left heart syndrome. Physiol Genomics. 2016, 48:912-21. 10.1152/physiolgenomics.00091.2016 